über die ausländischen Volksgruppen in den Philippinen, den Chinesen (39 Seiten + 12 S. [entbehrliche] Dokumente), Japanern (20 Seiten) und Indern (6 S.), sind 24 Fotos, davon acht Luftaufnahmen, von Manila sowie zwei Karten beigegeben. Ein nicht nur wegen des hohen Preises sehr entbehrliches Buch.

Rolf Hanisch

Wolfgang Treue

Die Jaluit-Gesellschaft auf den Marshall-Inseln 1887-1914

Ein Beitrag zur Kolonial- und Verwaltungsgeschichte in der Epoche des deutschen Kaiserreichs

Schriften zur Wirtschafts- und Sozialgeschichte Bd. 26

Duncker \& Humblot, Berlin 1976, 197 S.

Die Arbeit wurde 1940 als Dissertation der Philosophischen Fakultät der Universität Berlin angenommen, durfte aber nicht veröffentlicht werden, da die MarshallInseln damals unter japanischem Mandat standen und eine Befassung damit als unerwünscht galt. Eine Veröffentlichung nach 36 Jahren wurde insbesondere deshalb befürwortet, weil die darin verarbeiteten Akten der preußischen Gesandtschaft in Hamburg durch Kriegseinwirkung verlorengegangen sind.

Der Inhalt der Arbeit befaßt sich vor allem mit der Firmengeschichte, aber auch mit der allgemeinen Verwaltung. Die Jaluit-Gesellschaft als eine der wenigen deutschen „Chartered Compagnies“, die immerhin 18 Jahre die deutschen Souveränitätsrechte ausübte (1888-1906) und bis 1914 die Wirtschaft der Marshall-Inseln beherrschte, ist auch kolonialgeschichtlich ein interessantes Phänomen.

$\mathrm{Da}$ die Jaluit-Gesellschaft eng mit Hamburg verbunden war und da der Verfasser 1941 im Deutschen Institut für außenpolitische Forschung in Berlin (einem Vorgänger des Instituts für Internationale Angelegenheiten) tätig war, liegt ein Hinweis auf seine Arbeit nahe. Erwähnenswert ist, daß die noch bestehenden deutschen Kolonialgesellschaften erst durch das Bundesgesetz v. 20. 8. 1975 über die Auflösung, Abwicklung und Löschung von Kolonialgesellschaften (BGBl. I, S. 2253) aufgehoben wurden.

Hellmuth Hecker

\title{
Leslie Wolf-Philips
}

Comparative Constitutions

Studies in Comparative Politics, MacMillan, London 1972

Die politikwissenschaftliche Beschäftigung mit Verfassungen leidet darunter, daß sie zwischen die Fächer fällt, da sich Juristen nicht mit der politischen Funktion von Verfassungen beschäftigen und Politologen sich nur bedingt an das Thema herantrauen. Das kleine Bändchen von Wolf-Philips bietet hier eine Grundlage, indem es einen Überblick über die verschiedenen Versuche gibt, Verfassungen $\mathrm{zu}$ kategorisieren und typologisieren. Nach den heute, insbesondere im angelsächsischen Raum, noch einflußreichen Ansätzen von Bryce und Wheare behandelt er deren Kritik durch Loewenstein und Azkin, die er für noch immer zu abstrakt hält, sowie als Beispiel für einen sozialistischen Ansatz die Arbeit von Kovacz. Anschließend entwickelt er selbst einen Katalog von zwölf Dichotomien (codified/ uncodified usw.), mit denen er Verfassungen vergleichend erfassen will. Für die Einführung in die Verfassungsvergleichung zweifellos ein nützliches Werk.

Brun-Otto Bryde 